\title{
EDITORIAL
}

\section{A Stronger than ever Journal on Space Sciences, Technology, Management and Applications}

\author{
Ana Cristina Avelar , Antonio F. Bertachini A. Prado²
}

$\mathrm{T}$ is first JATM issue of 2014 is a very special one, and will be a landmark in the history of the journal. Starting on this number, an association was made between JATM and JAESA (Journal of Aerospace Engineering and Applications), the journal created by the Associação Aeroespacial Brasileira (AAB). Both periodicals will combine their efforts and merge into a single journal. This combination will allow a better use of financial and human resources, which were, before the present issue, divided into two journals that cover about the same topics, were based in neighboring institutions, and had many editors and referees in common. Publications made until the year 2013 will be preserved in their original archives. From January 2014, the joint publication will appear under the name of JATM. Submissions to the merged journal should be made at http://www.jatm.com.br. The editors and referees will form a single team. It was also decided to keep both editors in chief, as each one brings experience and individualized vision, which certainly will enrich the discussions and make decision on publication of articles easier, since aerospace areas present specific and varied aspects. Looking back in time, the JAESA was created in 2007 as a technical journal, objective of which was publishing papers of research and development in aerospace engineering and space sciences, as well as applications in both the areas developed internationally. It was organized to cover topics related to space programs around the world and their applications, as well as theoretical developments in those areas and related ones, like astronomy, numerical methods, control systems, and so on. The first number of the journal is dated January-April 2008, and a total of 12 issues were published in the last 6 years. The geographical distribution of authors, referees, and editors was very large, what assured a really international journal. Several important steps were made by the journal, including the important indexation at SCOPUS. On the other side, JATM was created in 2009 in the Instituto de Aeronáutica e Espaço (IAE), with the purpose of providing the scientific community with the high-quality results of research

\footnotetext{
三 1.Instituto de Aeronáutica e Espaço, São José dos Campos/SP, Brazil | Ana Cristina Avelar received a Mechanical Engineering degree from the Universidade Federal de Itajubá [UNIFEI], in 1994. She received the MSc and Doctor degree in Mechanical Engineering in the area of Thermal and Fluids Sciences in 1997 and 2001 respectively, by the Universidade Estadual de Campinas (UNICAMP). She started in the Instituto de Aeronáutica e Espaco (IAE), as a researcher in 2002 . She has paint (PSP). From September 2010 to September 2011 she carried out and a post-doc stage in the Laboratoire de Mécanique de Lille, Lille, France, working with Tomographic PIV. Today she is also a professor in the post-graduation program in Sciences and Space Technologies, PG-CTE, in the Instituto Tecnológico de Aeronáutica (ITA). Email: editor@jatm.com.br

2.Instituto Nacional de Pesquisas Espaciais, São José dos Campos/SP, Brazil | Antonio F. Bertachini A. Prado has 25 years of experience in research and educational activities in the aerospace field. He obtained five academic degrees: Ph.D. (1993) and Master (1991) in Aerospace Engineering from the University of Texas at Austin [USA], Master in Space Science/Orbital Mechanics (1989) from the Instituto Nacional de Pesquisas Espaciais (INPE) in Brazil, BA in Physics [1986) and Chemical Engineering (1985) from Universidade de São Paulo in Brazil. In 1989 he also participated in the summer session of the International Space University, in Strasbourg, France. He is currently President of the Board of the Graduate School at INPE. He also has the following positions: Advisor in the field of Astrodynamics for Conselho Nacional de Desenvolvimento Científico e Tecnológico (CNPq) since 1995, Full Professor of the Universidade Estadual Júlio de Mesquita Filho, and Associate Fellow of American Institute of Aeronautics and Astronautics (AIAA). Email: antonio.prado@inpe.br
} 
and development in the aerospace area, offering public access to all of its contents and generating a greater global exchange of knowledge. In 2011, JATM became an official publication from Departamento de Ciência e Tecnologia Aeroespacial (DCTA) and started receiving financial support from the prestigious Fundação Conrado Wessel (FCW). This financial support has been a very important means for guaranteeing the journal periodicity and punctuality, essential for a high-quality job. Today, almost 6 years after its creation, JATM publishes, without charging any fee from the authors or readers, papers from important institutions around the world. It has an Editorial Board composed of recognized researchers from several countries in different specialties, and it is indexed in 16 important databases, among them SCOPUS, LATINDEX, REDALYC, EBSCO Publishing, and PERIÓDICOS CAPES. JATM is quarterly published, and its website has more than a thousand of hits per month and, more important, from different countries.

Based on the individual success, discussions related to the association of both journals have been made for several years. This action would be beneficial for the divulgation of science, the ultimate goal of both publications. In the end of 2013, it was clear that merging the publications would be the best thing to do. A single journal with a stronger editorial committee would increase the quality of all the steps involved in the production of the journal, from recruiting authors, evaluation and selecting papers, publication of the issues and divulgating it. After the decision of the unification was taken, it was necessary to plan the next steps. The first action required was the decision about the name of the new journal. A different title would require starting over again several important steps, since all the indexations and citations accumulated in the last 6 years would be lost. Therefore, it was decided to keep the title as JATM, which is a bit more generic, because it includes the "management" activities, very important in the space activities today. So, despite of the title, the publication is essentially a result of the combination of both the journals and is now fully supported by the DCTA, FCW, and AAB. After that, a combination of the editorial members from the two journals was made, trying to find the best geographical affiliation and technical distribution for the editorial board. The new Editorial Board of JATM very well shows the power of the combined journal: there are now 49 editors, from 12 different countries, covering 25 fields of expertise. Those numbers show a strong international journal able to cover all the fields of space activities. As a final step, a strong effort has been carried out in divulgating the news for all possible authors and readers, in an attempt to get an increase in the number of submissions.

We sincerely hope that this unification will create a stronger journal and that the future will prove that this decision was right.

Once again, we thank all our collaborators: authors, referees, and editors of both the journals for their important work in the last years, and we ask them to continue supporting our unified journal. 